steady, restoring a satisfactory ventilation. ${ }^{3-5}$ In our case an extreme condition of vanishing of the muscular support of the hemidiaphragm forced us to perform an alternative technique with optimal functional results.

The aim of this technique was as follows: (1) tailoring a plastic correction with a prosthetic mesh with a greater pressure-proof guarantee compared with that seen in the traditional surgical techniques; (2) creating an area of thickness corresponding to a new durable central tendon able to resist the constant abdominal pressure exerted by the viscera; and (3) avoiding a direct contact between the prosthesis and the lung parenchyma.

Optimal functional results and complete anatomic integration led us to believe that this technique could be worthy of consideration in the treatment of major diaphragmatic eventration.

\section{References}

1. Mouroux J, Venissac N, Leo F, Alifano M, Guillot F. Surgical treatment of diaphragmatic eventration using video assisted thoracic surgery: a prospective study. Ann Thorac Surg. 2005;79:308-12.

2. Moroux J, Padovani B, Poirier NC, Benchimol D, Bourgeon A, Deslauriers $\mathrm{J}$, et al. Technique for the repair of diaphragmatic eventration. Ann Thorac Surg. 1996;62:905-7.

3. de Perrot M, Schweitzer A, Spiliopoulos A, Licker M. Early improvement of respiratory function after surgical plication for unilateral diaphragmatic paralysis. Eur J Cardiothorac Surg. 1998;13:206-8.

4. Moon SW, Wang YP, Kim YW, Shim SB, Jin W. Thoracoscopic plication of diaphragmatic eventration using endostaplers. Ann Thorac Surg. 2000;70:299-300.

5. Hwang Z, Shin JS, Cho YH, Sun K, Lee S. A simple technique for the thoracoscopic plication of the diaphragm. Chest. 2003;124:376-8.

\title{
An unusual case of lateral pulmonary hernia
}

\author{
Francesco Petteruti, MD, ${ }^{a}$ Paolo Pepino, MD, ${ }^{\text {a }}$ Giuseppe De Luca, MD, ${ }^{\mathrm{b}}$ Salvatore Griffo, MD, ${ }^{\mathrm{b}}$ Luigi Di Tommaso, MD, \\ and Paolo Stassano, MD, ${ }^{\mathrm{b}}$ Naples, Italy
}

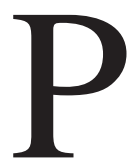

ulmonary hernia is a rare occurrence and may be congenital or acquired, the latter usually being a consequence of thoracic trauma. We report an unusual case of large lateral pulmonary hernia through a chest wall defect in a 70-year-old man involved in a motorcycle accident.

\section{Clinical Summary}

A 70-year-old obese man was involved in a high-speed motorcycle accident. Initial evaluation at the scene revealed a Glasgow Coma score of 14 , left shoulder luxation, cranial trauma with left hemophthalmos, and multiple rib fractures. His blood pressure was 110/65 mm Hg, and his heart rate was 105 heart beats/min. At admission to our hospital, the patient had severe chest pain and dyspnea. Physical examination revealed a large subcutaneous emphysema involving the chest, neck, and left superior arm. He was in severe respiratory acidosis. Radiography examination revealed a left humerus fracture, a left pneumothorax, multiple rib fractures, a large left-sided effusion, and a huge subcutaneous emphysema. A total-body computed tomography (CT) scan revealed a left orbital fracture, a left pneumothorax, multiple rib fractures, a left hemothorax, and a large lateral lung hernia protruding through a

From the Cardiothoracic Surgery Unit, Clinica Pineta Grande Castelvolturno $(\mathrm{CE}){ }^{\mathrm{a}}$ and Cardiothoracic Surgery Unit, University Federico II, ${ }^{\mathrm{b}}$ Naples, Italy.

Received for publication Feb 11, 2006; accepted for publication March 15, 2006.

Address for reprints: Francesco Petteruti, MD, via Lauria 38, 81100 Caserta, Italy (E-mail: tea41273@ libero.it).

J Thorac Cardiovasc Surg 2006;132:189-90

$0022-5223 / \$ 32.00$

Copyright $\odot 2006$ by The American Association for Thoracic Surgery doi:10.1016/j.jtcvs.2006.03.019 chest wall defect between the sixth and seventh ribs with contralateral pulmonary contusion (Figure 1).

The patient was rushed to the operating room. General anesthesia was carried out with double-lumen endotracheal intubation, and in right lateral decubitus the chest was entered between the sixth and seventh intercostal space. The serratus magnus and intercostal muscles were torn, the left lung was carefully freed from rib spicules, and the hemothorax was evacuated. When the left lung was reexpanded, the parenchyma went out through a large lateral chest defect. At this point the surgical incision was widened as a regular thoracotomy. A careful examination excluded bronchial, vascular, diaphragmatic, and pericardial injuries. Small pulmonary lacerations and rib fractures were repaired, the pleural cavity was irrigated, and 2 chest tubes were inserted. A doublesheet, large $(12 \times 6 \mathrm{~cm})$ Prolene mesh was inserted on the inner side of the thoracic cage to completely close the chest defect. The serratus magnus muscle was repaired, and the chest was closed. The patient was transferred to the intensive care unit where he was extubated 3 hours later. The postoperative course was uneventful, and the chest tubes were removed after 6 days. The patient was discharged on the tenth postoperative day. Six months postoperatively, he was in good clinical condition. The CT scan revealed the complete healing of the pulmonary lesion (Figure 2).

\section{Discussion}

Lung hernia, protrusion of pulmonary parenchyma with pleural membranes through a defect of the thoracic wall, is a rare entity. The cause is acquired in approximately $80 \%$ of cases and of traumatic origin, and this may not become apparent for several weeks to years after the trauma. Sixty-five per cent of lung hernias have a thoracic location. ${ }^{1}$ The thoracic cage has inherent weakness anteriorly, near the sternum, and posteriorly, near the vertebral bodies, where there is a single layer of intercostal muscle. The 


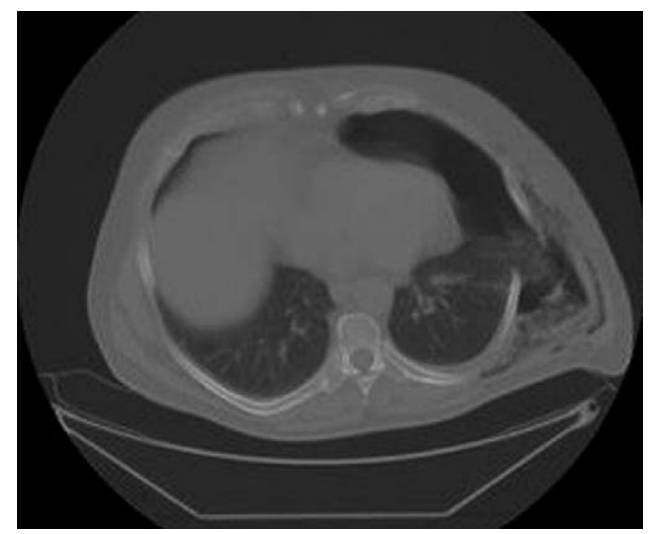

Figure 1. Thoracic computed tomography (CT) scan: large lateral lung hernia.

anterior part of the chest wall is involved in the majority of cases because, presumably, it lacks the muscular support supplied posteriorly by the trapezius, latissimus dorsi, and rhomboideus muscles. $^{2}$ Symptoms are usually minimal, and sometimes the patient may be asymptomatic. Chest radiography is helpful in establishing the diagnosis even if subcutaneous posttraumatic emphysema and chest wall hematoma may confuse the clinical picture. ${ }^{3} \mathrm{CT}$ scan is useful because it defines the dimensions of the lung hernia and provides valuable information on the thoracic cage and pleural spaces. ${ }^{1}$

Small pulmonary hernia can be treated conservatively by thoracic strapping, even if primary suture and fixation of adjacent ribs may lead to an early recovery. Larger hernias, with persistent pain and/or entrapped lung, require surgical intervention and may require the use of muscle flaps ${ }^{4}$ or prosthetic mesh to close the defect. $^{5}$

This case was unusual because the lung hernia was located on the lateral side of the chest, which is usually protected by 2 muscles, the intercostal and serratus, and because it was missed on the plain chest radiography. The entrapment of lung parenchyma on fractured ribs, as in our patient, is unusual, ${ }^{5}$ and we completely

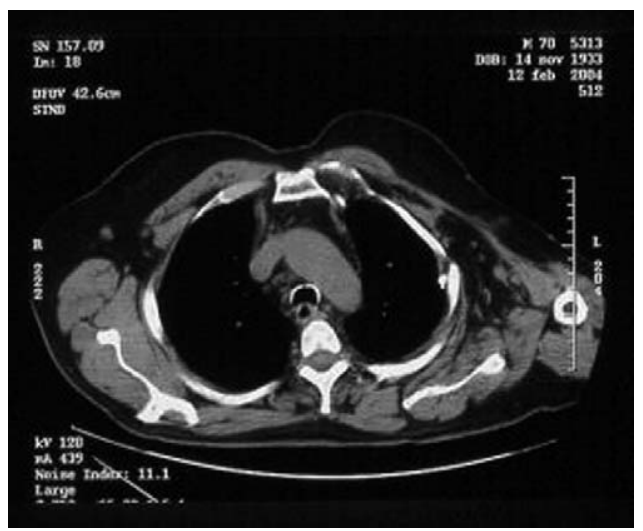

Figure 2. Postoperative thoracic computed tomography (CT) scan: complete resolution of the pulmonary lesion.

freed the lung without any pulmonary resection but by suturing the torn parenchyma to prevent air leaks. The use of a large Prolene mesh stabilized the surgical correction.

\section{Conclusion}

CT scan is mandatory for an early and complete diagnosis, and prompt surgical management without lung resection. The use of a prosthetic mesh can give excellent immediate and long-term results.

\section{References}

1. Glenn C, Bonekat W, Cua A, Chapman D, McFall R. Lung hernia. Am J Emerg Med. 1997;15:260-2.

2. Lang-Lazdunski L, Bonnet PM, Pans F, Brinquin L, Jancovici R. Traumatic extrathoracic lung herniation. Ann Thorac Surg. 2002;74: 927-9.

3. Getzoff A, Shaves S, Carter Y, Foy H. Traumatic lung herniation. Am J Roentgenol. 1999;172:1032.

4. Jacka MJ, Luison F. Delayed presentation of traumatic parasternal lung hernia. Ann Thorac Surg. 1998;65:1150-1.

5. Arslanian A, Oliaro A, Donati G, Filosso PG. Posttraumatic pulmonary hernia. J Thorac Cardiovasc Surg. 2001;122:619-21. 